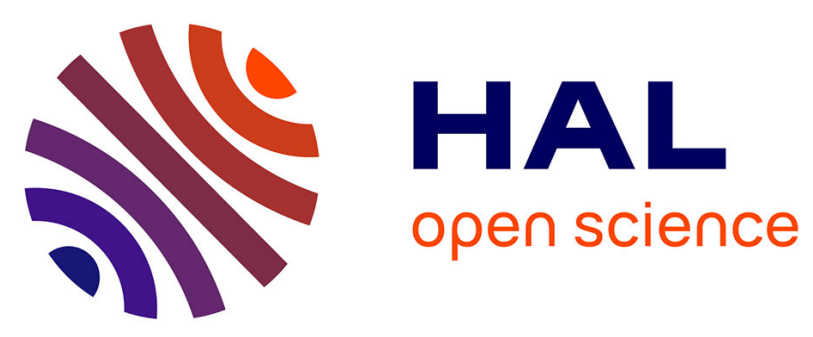

\title{
Women in ICT: Opportunities for Their Inclusion in an International Labor Market
}

Ana M. González, Beatriz Revelles, Elisabet Almeda, Núria Vergés Bosch, José S. García

\section{- To cite this version:}

Ana M. González, Beatriz Revelles, Elisabet Almeda, Núria Vergés Bosch, José S. García. Women in ICT: Opportunities for Their Inclusion in an International Labor Market. 6th IFIP World Information Technology Forum (WITFOR), Sep 2016, San José, Costa Rica. pp.171-177, 10.1007/978-3-31944447-5_16. hal-01429745

\section{HAL Id: hal-01429745 \\ https://hal.inria.fr/hal-01429745}

Submitted on 9 Jan 2017

HAL is a multi-disciplinary open access archive for the deposit and dissemination of scientific research documents, whether they are published or not. The documents may come from teaching and research institutions in France or abroad, or from public or private research centers.
L'archive ouverte pluridisciplinaire HAL, est destinée au dépôt et à la diffusion de documents scientifiques de niveau recherche, publiés ou non, émanant des établissements d'enseignement et de recherche français ou étrangers, des laboratoires publics ou privés.

\section{(c)(1)}

Distributed under a Creative Commons Attribution| 4.0 International License 


\title{
Women in ICT: Opportunities for Their Inclusion in An International Labor Market
}

\author{
Ana M. González ${ }^{1 * 1}$, Beatriz Revelles ${ }^{1}$, Elisabet Almeda ${ }^{2}$, Núria Vergés Bosch ${ }^{2}$, \\ and José S. García ${ }^{3}$ \\ GENTIC, Open University of Catalonia, Barcelona, Spain \\ \{anagonzalezram, brevelles\}@uoc.edu \\ 2 \\ Copolis, University of Barcelona, Barcelona, Spain \\ \{elisabet.almeda, nuria.verges\}@ub.edu \\ Department of Sociology, University of La Laguna, Spain \\ josamaga@ull.es
}

\begin{abstract}
ICT is a key sector for developing contemporary economies and it entails an opportunity for increasing the employment rates internationally. Women were traditionally underrepresented; therefore, we need to reinforce their role in the international labor market. Before the implementation of positive actions, we need to know what is the situation and experiences of women in ICT workplaces. Through the Spanish Labor Force Survey we analyze the evolution of women. Despite the economic crisis, data shows that women have as good job prospects as men in the ICT labor market. However, women present higher levels of qualifications than men in the same category which may be interpreted as a sign of gender discrimination. Significantly, women display more critical opinions regarding the average work week.
\end{abstract}

Keywords: Female talent; incorporation of women in ICT; labor conditions; employment.

\section{Introduction}

The low number of women in ICT was widely discussed in the literature [1,2,3,4] as a dysfunction of the education and the labor market. The lack of women in these areas evidences social injustice, particularly, in regards to the importance and great opportunities of the ICT sector for future employment $[5,6]$. Apparently, women are less attracted compared to men, as shown by the low number of women in the ICT workforce. Male predominated professions tend to create unfriendly environments for the few women in the workplace. Literature attributes this as the primary cause of the exclusion of women from ICT sectors $[7,1,8]$. This work attempts to shed light on the situation of women in the Spanish labor market in relation to ICT employment. The role of women in the labor market, not specifically in ICT sector, has been traditionally linked to insecurity and poor conditions because women hold subordinate positions. In this work, we examine to what extent male

This work was supported by the projects: GENTALENT, 2014ACUP00013, ACUP (Association of Catalan Public Universities) and La Caixa Foundation, GENCPOLIS CSO2014-55556-P, and CIEDES CSO2011-30179-C02-01. 
and female employment shows similar characteristics, or otherwise, in the ICT sector. The incorporation of women in the labor market has to do with maternity and second shift [9]. Labor conditions within the ICT sector affect women seriously, because they require total availability, long-hours and extra work, making difficult a work-life balance [10].

During the last decades, multinational corporations have implemented programs to mentor and attract women in their professional staff. However, positive actions have shown limited results [5]. The percentage of women in private organizations remains relatively low, around $20 \%$, and they occupy management and commercial positions rather than technological ones. It seems some positions are still male predominated. Therefore, we need to collect more information about how to tackle female barriers in the workplace and create more attractive environments for women in ICT sector. We need to send positive messages to women in STEM (science, technology, engineering and mathematics) in order to facilitate their incorporation into the ICT sector [11]. Role model programs are encouraging women in university but the low number of women is still a problem. Likewise, managers in the TIC sector show an increasing interest to including women, as such female talent has value for them [12]. We need to know more information about the perception of women towards the ICT employment. Female opinion about their labor conditions provides information about what problems are perceived as obstacles due to gender issues. The Labor Force Survey is an international survey that explores labor participation across 28 Member States of the European Union [13].

The paper comprises three sections. In the first section we introduced the article. In the second section we present the objectives and methodology. The third section explores the situation of women in the ICT sector and the main findings of our work. Finally, we summarize the main conclusions of this paper and make some recommendations for future implementation in education and business organizations.

\section{Objectives and methodology}

The objective of this work aims to provide feasible data about the participation of women in the ICT workforce. This work analyzes working conditions of women in the ICT sector according to the Spanish Labor Force Survey. This survey is a large household sample survey providing quarterly results on labor participation of people aged 15 and over as well as on persons outside the labor force. European countries provide information about their national labor workforce in accordance with Council Regulation (ECC) No. 577/98 of 9 March 1998. From the application of this survey, the microdata contain information about several dimensions of labor conditions, unemployment situation, in a representative sample per regions, as well as sectors of activity. Spanish Labor Force Survey covers 60.000 households and 150.000 people.

Some methodological notes about the ICT sector are necessary for understanding the findings of this study. We use the classification of technological occupations (National Classification of Occupations CNO) by the National Institute of Statistics, as proposed by the ILO in 2011. Occupational categories cover professionals in information technology (code 27 of the National Classification of Occupations (CNO) 20) which comprise analysts and software designers and multimedia specialists in databases and computer networks; technical positions in science and engineering (code 31); technicians and information technology and communications (code 38) that comprise operations and information technology user support, computer programmers and technicians in audiovisual recording, broadcasting and telecommunications.

\section{Women in the ICT labor market}

ICT employment is a relative small percentage of the total Spanish employment (4\%). This sector of activity only represents $1.4 \%$ of the workers; however, the importance of the economic sector increases the relevance for the workforce. The representation of women in these groups of occupations is very limited $0.6 \%$ in comparison with men, which is $2.1 \%$ of the total population. Women represent around $24 \%$ of the total employees in the ICT sector. A characteristic of this sector is the high rate of employment for both men and women professionals which supports the hypothesis of good expectations of employment for male and female workers. According to the Labor Force Survey in 2015, the unemployment rate (people in ICT sector who left 
the labor market last year) reaches 3.2\%, similar for men and women in the workforce. Employment and unemployment rates from 2008 to 2013 in the ICT sector show a steady situation, even if Spain was severely affected by the economic crisis, ICT employment displays a positive evolution. The economic crisis destroyed 3.5 million jobs, mostly in two activity sectors 'building construction' and 'specialized construction activities'. Consequently, the ICT sector presents a healthy situation that positively affects male and female workforce.

Table 1 presents rates of employment of men and women and shows a gender gap in the ICT sector. The percentage of women is smaller than men in every age group as a result of low female presence generally. Additionally, the female workforce displays different percentages in occupation rates between age groups. Women between 46-64 years old have the lowest percentages $(0.6 \%)$ which reflects a historical underrepresentation of women in the ICT sector. The youngest women (25-30 years old) are 2.5 less represented than men in the same age group. This data suggests that there is as low integration of women in the ICT labor sector despite an increasing number of female graduates. These results indicate that the implementation of positive actions is necessary for the inclusion of women in ICT environments.

Table 1. Rates of employment in ICT sector by age groups

\begin{tabular}{|c|c|c|c|}
\hline & Men & Women & Total \\
\hline $25-30$ & $3.9 \%$ & $1.4 \%$ & $2.6 \%$ \\
\hline $31-45$ & $5.3 \%$ & $2.0 \%$ & $3.7 \%$ \\
\hline $46-64$ & $2.8 \%$ & $0.6 \%$ & $1.7 \%$ \\
\hline Total & $3.6 \%$ & $1.1 \%$ & $2.4 \%$ \\
\hline
\end{tabular}

Source: EPA 2015, INE second term

We have looked at employment security in the ICT labor market from a gender perspective. Table 2 displays gender differences in ICT employment. The results indicate similar percentages of men and women with regard to temporary employment and part-time employment. In the case of temporary employment, women show a slight difference (13.8\% men; $15.8 \%$ women) but the effect is very small and lacks statistical significance. Parttime rates are similar to men and women rates from other sectors. However, we explore reasons why men and women are part-time employees, displaying women argue family to a greater extent than men $(33.5 \%$ women; $4.5 \%$ men).

Table 2. Gender differences regarding employment typology

\begin{tabular}{|c|c|c|c|}
\hline & Men & Women & Total \\
\hline$<35$ hours & $5.2 \%$ & $4.7 \%$ & $5.1 \%$ \\
\hline Temporary jobs & $13.8 \%$ & $15.8 \%$ & $14.3 \%$ \\
\hline Part-time & $3.4 \%$ & $5.5 \%$ & $3.9 \%$ \\
\hline
\end{tabular}

Source: EPA 2015, INE second term

Working long hours is identified as a factor which contributes to creating an unfriendly environment in the ICT sector $[14,15,16]$. The percentage of employees working overtime in the ICT sector is higher than in any other activity sector, although men and women work the same amount of extra hours, with being slightly higher ( $9.5 \%$ men; $9.8 \%$ women). This indicates that women undertake the same work as men and is disadvantage for professional mothers [1, 3, 4]. According to the Labor Force Survey 2015, women would like to work fewer hours than they actually do, even accept a pay cut. The Labor Force Survey asks questions about preferences for working hours and the willingness to accept a reduction in wages. Findings show that $9.8 \%$ of women would accept a reduction in working hours compared to $4.6 \%$ of their male counterparts. Moreover, $64.2 \%$ of women would prefer to accept pay cuts, while $56.7 \%$ of men would be willing to accept to work more hours 
than women in the ICT sector. The survey shows gender differences regarding the work attitudes and life styles of men and women. Results suggests that women suffer severely the long working hours in the ICT sector, since they accept lower wages instead of spending more free time outside work.

We identify that a work-life balance is as a handicap for the female workforce $[3,4,9]$. Despite the effectiveness of positive policies, women are negatively affected by social gender roles that continue distributed traditionally. In relation to family care, the Labor Force Survey includes some questions that allow us to know how men and women are living with children under 17 years old. As a result, we know how family matters in the distribution of male and female workforce in the table 3 . The data show that there is not a difference between men and women with children under 17 years old in the ICT sector ( $42.5 \%$ men while $47.7 \%$ women). These results suggest that women still have to compromise time for care, although we do not know the extent of coresponsibility at home nor the effect on external support for housekeeping. Table 3 displays a greater gender balance among ICT workers than among non-ICT/non-qualified workers (50.4\% men while $56.7 \%$ women), but a greater gap than other qualified occupations (49.4\% men while $51.8 \%)$.

Table 3. Men and women with children under 17 years old

\begin{tabular}{|c|c|c|c|}
\hline & Men & Women & Total \\
\hline ICT occupations & $42.5 \%$ & $47.7 \%$ & $43.8 \%$ \\
\hline $\begin{array}{c}\text { Other qualifed } \\
\text { occupations }\end{array}$ & $49.4 \%$ & $51.8 \%$ & $50.5 \%$ \\
\hline $\begin{array}{c}\text { Non-ICT/ Non- } \\
\text { qualified } \\
\text { occupations }\end{array}$ & $50.4 \%$ & $56.7 \%$ & $53.3 \%$ \\
\hline Total & $49.6 \%$ & $55.3 \%$ & $52.2 \%$ \\
\hline
\end{tabular}

Source: EPA 2015, INE second term

Previous studies suggest that women have to make greater efforts than men to achieve similar positions in professional careers because male dominated environments discourage women from pursuing higher milestones. In addition, they indicate that female work is undervalued because of gender stereotypes $[2,11,12$, $13,14,15]$. We examine the academic credentials in the male and female workforce, checking whether women need to demonstrate greater merit than men to achieve the same position on the professional ladder. Some questions of the Labor Force Survey point to indirect ways to investigate overqualification. Data from Labor Force Survey 2105 suggest that women are more qualified than men in the ICT sector using two different indicators. Firstly, we compare overqualification by measuring more than one standard deviation from the average years of schooling by total population included in the occupation category. Through this indicator, women in the ICT sector display overqualification because they show an almost doubled ratio (19.4\%) to their male counterparts (10.7\%) in each sex group category. Secondly, we compare overqualification as a deviation of the average number of schooling years. According to this second indicator, data shows that $17.7 \%$ of women (while $13.3 \%$ of men) complete more years in school than the general population. There is gender statistical significance but the relationship between both variables (sex of workers and schooling years) is weak.

\section{Conclusions}

The results of this work confirm our primary findings of qualitative studies [17], concerning major obstacles faced by women in male predominated environments. The main problem suggested by responses from women interviewees in the Labor Force Survey is the time demanding environment of the ICT sector. The findings show women would accept lower wages to reduce their working schedule. Women are critical of the length of the work by week in the ICT sector. We can suggest that working hours are more stressful for women than men because of their impact on the work-life balance. The labor Force Survey shows similar percentages of male and female workers in the ICT sector with children living at home under 17-year-old, which suggests female double shift. The long-hours climate in the workplace probably clashes with care roles at home. It would be 
interesting to compare differences between countries regarding diverse culture and persistence of gender roles. A future line of research will provide more evidence about northern and southern countries regarding motherhood and professional orientation of women by countries.

This work also confirms the opportunity offered by the ICT sector for qualified women. Firstly, the employment rates should be an incentive for women who have higher percentages than men in unemployment rates (although it depends on wiping out gender bias in the workplace). The ICT sector was affected in a lesser extent by Spanish economic situation, maintaining employment rates and labor conditions compared to the rest of the economic activity. Unlike building, construction and banking sectors, ICT sector has shown steady rates of employment. Women employees also take advantage of the positive characteristics of the ICT sector.

Although the population employed in this sector accounts for $4 \%$ of total employment, it expects a positive growth in the future which opens new avenues to qualified professionals [5]. This prospect should encourage young women to seek this educational qualifications and vocational training required by the ICT sector. The higher education and the labor market should adapt their structures in order to attract more young women into this traditionally male environment and encourage them to develop stimulating careers in this sector. Data suggests that encouraging women to enter technological vocations depends on employment policies to reverse the segregation in the labor market and create women friendlier workplaces [13]. Although employment conditions include a great number of work-life balance measures, the opinions of women in the Labor Force Survey suggest it is still a stressful context for women workers. This impediment is naïve because this is the most innovative sector, with total flexibility and creativity as fundamental pillars of working hours. The challenge of the ICT sector will be to implement effective measures to adapt its environment to meet the needs of women, relaxing daily work life in the institutions.

Overqualification points to the persistence of gender bias and discriminatory situations in the ICT labor market. It points to fighting against employers (headhunters and other human resources recruiters) and its prejudices related to gender and age. Our suggestion entails training courses for reinforcing abilities and competences in young people. Mentoring programs seem very positive for creating a culture of confidence in the companies and from bosses to young workers. Moreover, mentoring programs are more effective if there is a transfer from business experience to higher school curricula, in order to bridge the gap between learning and professional experience. Working jointly together, from private to public spaces, benefits global competitiveness.

The management of working hours in the workplace is a main factor that contributes to difference between men and women. Women prefer to work shorter hours which suggests that they suffer an increasing pressure on their careers. Care responsibility is a well-known cause of delaying careers for women in the labor market, but we suggest that we should consider other factors related to less stressful conceptions about life and health. The gender gap comes not only from personal choices but also from the dynamics of business world. In our view, companies should deal with a different concept of working-time to attract female and talent. Women accept fewer working-hours, even if they receive lower wages, while men feel this need to a lesser extent. These differences between men and women create asymmetries even where there are gender sensitive policies.

Diversity policy is considered an opportunity to create new perspectives and solutions in the ICT sector. Some international corporations implement diverse models of management for attracting talent concerning the attraction of diverse people (according to their origin, sexual orientation, religion, culture, gender and other characteristics). However, the effectiveness of these policies depend on the cultural change rather than the simple incorporation of people. Diverse talent entails the decision of accepting a different kind of knowledge that inspires creativity and innovation. Classical structures in companies, concerning on-site orientation and rigid hours, could reach its limit. By contrast, the organization of culture tends to erase differences between male and female workers (or diversity of employees) because of a strong tendency to respect the aims of the corporation.

\section{References}

1. Cockburn, C. (1983). Brothers: Male Dominance and Technological Change. London: Pluto Press. 
2. Kvande, E. (1999). "In the Belly of the Beast: Constructing Feminities in Engineering Organizations". The European Journal of Women's Studies, 6: 305-328.

3. Margolis, J. and Fisher, A. (2002). Unlocking the Clubhouse Women in Computing. Cambridge, Massachusetts: The MIT Press.

4. Castaño, C. (ed.) (2008). La segunda brecha digital. Madrid: Ediciones Cátedra.

5. Directorate-General for Internal Policies (2015). "Encouraging STEM Studies for the Labour Market'.

IP/A/EMPL/2014-13 PE 542.199.

6. Gill, R. (2002). "Cool, creative and egalitarian? Exploring Gender in Project. Based New Media Work in Europe”.

Information, communication and Society. 5(1): 70-89.

7. Rommes, E., Bos, M. and Geerdink, J. O. (2011). "Design and Use of Gender Specific and Stereotypical Toys".

International Journal of Gender, Science and Technology, 3(1): 184-204.

8. Bystydzienski, J. M. and Bird, S. (2006). Removing Barriers. Women in Academic Science, Technology, Engineering, and Mathematics. Bloomington: Indiana University Press.

9. Hochschild, A. and Machung, A. (1990). The Second Shift. Avon Books: New York.

10. De la Rica, S. (2007). "Segregación ocupacional y diferencias salariales por género en España: 1995-2002”, FEDEA [http://www.fedea.net/documentos/pubs/dt/2007/dt-2007-35.pdf].

11. Etzkowitz, H., Uzzi, B. and Kemelgor, C. (2000). Athena Unbound: The Advancement of Women in Science and Technology. Cambridge: Cambridge University Press.

12. http://ec.europa.eu/eurostat/web/microdata/european-union-labour-force-survey.

13. http://www.niemanlab.org/2011/05/mit-management-professor-tom-malone-on-collective-intelligence-and-thegenetic-structure-of-groups/.

14. Faulkner, W. (2007). "Nuts and Bolts and People: Gender-Troubled Engineering Identities". Social Studies of Science, 37(3): 331-353.

15. Faulkner, W. (2009). "Doing Gender in Engineering Workplace Cultures: II. Gender In/Authenticity and the In/Visibility Paradox". Engineering Studies, 1 (3): 169-89.

16. Faulkner, W. (2014). “Can Women Engineers be 'Real Engineers' and 'Real Women?' Gender In/Authenticity in Engineering”. En Gender in Science and Technology. Interdisciplinary Approaches, Waltraud, Ernst and Ilona Horwath, 187-203. Bielefeld: Transcript Verlag.

17. Vergés, N., González, A. M. and Almeda, E. (2014). "Doing and Undoing Genders and Information and Communication Technologies". En Proceedings of the XV International Conference on Human Computer Interaction (Interacción '14). ACM, New York, (80): 2. DOI=http://dx.doi.org/10.1145/2662253.2662333. 